\title{
Vitamin Requirements for Growth of Myxamoebae of Dictyostelium discoideum in a Defined Medium
}

\author{
By D. J. WATTS \\ Biochemistry Department, The University, Sheffield S10 2 TN
}

(Received 2 July 1976)

S UMMARY

Myxamoebae of Dictyostelium discoideum strain Ax-2 were adapted to growth in a medium containing B vitamins, a vitamin-free tryptic digest of casein, soluble starch and inorganic salts. Omission of vitamins from this medium confirmed that D-biotin, thiamin, folate and $\alpha$-lipoate are essential for myxamoebal growth and showed that riboflavin or flavin mononucleotide is also required. No requirement for other vitamins or growth factors could be detected. A defined medium was developed by replacement of the tryptic digest of casein with a mixture of $20 \mathrm{~L}$-amino acids and addition of Tween 80 . Tween 80 caused starch precipitation in the medium and this seemed essential for stimulating growth of the myxamoebae.

\section{INTRODUCTION}

Myxamoebae of the cellular slime mould Dictyostelium discoideum strain Ax-2 grow axenically in a medium containing yeast extract, bacteriological peptone and inorganic salts (Watts \& Ashworth, 1970), but all previous attempts to grow them in a simpler defined medium have failed. It seemed possible that such attempts might be successful if more were known about the nutritional requirements for growth of the myxamoebae. Some of the vitamin requirements were determined recently (Watts \& Guest, 1975) and the remaining vitamin requirements are described in this paper together with a defined medium that supports growth of myxamoebae.

\section{METHODS}

Growth of Dictyostelium discoideum. Myxamoebae of strain Ax-2 (ATCC24397) were grown initially in $\mathrm{HL}_{5}$ medium [ $\mathrm{I} 0 \mathrm{~g}$ bacteriological peptone and $5 \mathrm{~g}$ yeast extract in $700 \mathrm{ml}$ $3.6 \mathrm{~mm}$-phosphate buffer $\left(\mathrm{Na}_{2} \mathrm{HPO}_{4} / \mathrm{KH}_{2} \mathrm{PO}_{4}\right) \mathrm{pH} 6 \cdot 7$ ] plus soluble starch (I5 mg ml $\left.\mathrm{ml}^{-1}\right)$. They were then adapted to growth in medium (TEV) containing a vitamin-free tryptic digest of casein (Tryptone) and five B vitamins (Table I). Finally, myxamoebae were grown in a defined medium (AV medium, Table 2) containing L-amino acids and vitamins.

Amoebae were grown at $23{ }^{\circ} \mathrm{C}$ in shake cultures of either $60 \mathrm{ml}$ medium in $250 \mathrm{ml}$ Erlenmeyer flasks or Io $\mathrm{ml}$ medium in $100 \mathrm{ml}$ Erlenmeyer flasks as described by Watts \& Ashworth (1970). Cultures were inoculated with myxamoebae to a density of $2 \times 10^{4}$ to $5 \times 10^{4}$ myxamoebae $\mathrm{ml}^{-1}$ and were subcultured when the myxamoebae had reached a density of $5 \times 10^{6}$ myxamoebae $\mathrm{ml}^{-1}$. After growth, samples of each culture were left for 7 days at 30 and $37^{\circ} \mathrm{C}$ on plates of SM medium (Sussman, 1966) to check that the cultures were not contaminated with other micro-organisms.

Vitamin mixture. This contained ( $\mu \mathrm{g} \mathrm{ml}^{-1}$ final concentration): riboflavin, 0.5 ; flavin mononucleotide, 0.5 ; nicotinic acid, $\mathrm{I} \cdot 0$; calcium $\mathrm{D}$-pantothenate, $\mathrm{I} \cdot 0$; thiamin. $\mathrm{HCl}, \mathrm{I} \cdot 0$; 
Table I. Composition of the TEV medium containing vitamin-free Tryptone and essential vitamins

The components were dissolved in $100 \mathrm{ml} 50 \mathrm{~mm}$-phosphate buffer $\left(\mathrm{NaH}_{2} \mathrm{PO}_{4} / \mathrm{K}_{2} \mathrm{HPO}_{4}\right)$ pH $6 \cdot 5$. The trace salts mixture contained $\left(\mathrm{g} \mathrm{l}^{-1}\right): \mathrm{ZnO}, 0 \cdot 4 ; \mathrm{FeCl}_{3} \cdot 6 \mathrm{H}_{2} \mathrm{O}, 5 \cdot 4 ; \mathrm{MnCl}_{2} \cdot 4 \mathrm{H}_{2} \mathrm{O}, 2 \cdot 0 ; \mathrm{CuCl}_{2}$. $2 \mathrm{H}_{2} \mathrm{O}, 0.17 ; \mathrm{H}_{3} \mathrm{BO}_{4}, 0.6 ; \mathrm{CaCl}_{2} .6 \mathrm{H}_{2} \mathrm{O}, 10.0$; and conc. $\mathrm{HCl}, 10 \mathrm{ml} \mathrm{l}^{-1}$. The components of the medium were sterilized in an autoclave for $20 \mathrm{~min}$ at $12 \mathrm{I}{ }^{\circ} \mathrm{C}$, except for tryptophan which was added after sterilization by filtration.

\begin{tabular}{|c|c|c|c|}
\hline Component & $\begin{array}{c}\text { Concn } \\
{\left[\mathrm{g}(\mathrm{I} 00 \mathrm{ml})^{-1}\right]}\end{array}$ & Component & $\begin{array}{c}\text { Concn } \\
{\left[\mathrm{mg}(100 \mathrm{ml})^{-1}\right]}\end{array}$ \\
\hline Vitamin-free Tryptone & $2 \cdot 0$ & L-Phenylalanine & 50 \\
\hline \multirow[t]{2}{*}{ Soluble starch } & $1 \cdot 5$ & $\begin{array}{l}\text { L-Tryptophan } \\
\text { L-Tyrosine }\end{array}$ & $\begin{array}{l}50 \\
20\end{array}$ \\
\hline & {$\left[\mu \mathrm{g}(100 \mathrm{ml})^{-1}\right]$} & & {$\left[\mathrm{ml}(100 \mathrm{ml})^{-1}\right]$} \\
\hline D-Biotin & 25 & $\mathrm{MnCl}_{2} \cdot 4 \mathrm{H}_{2} \mathrm{O}\left(0.2 \mathrm{~g} \mathrm{l}^{-1}\right)$ & 0.5 \\
\hline Flavin mononucleotide & 25 & $\mathrm{MgSO}_{4} \cdot 7 \mathrm{H}_{2} \mathrm{O}\left(1 \circ \mathrm{g} \mathrm{l}^{-1}\right)$ & 0.5 \\
\hline Folic acid & 125 & Trace salts & $0 . I$ \\
\hline DL- $\alpha$-Lipoic acid & 50 & & \\
\hline Riboflavin & 25 & & \\
\hline Thiamin. $\mathrm{HCl}$ & 50 & & \\
\hline
\end{tabular}

Table 2. Composition of the defined AV medium

The components were dissolved in $100 \mathrm{ml} 50 \mathrm{~mm}$-phosphate buffer $\left(\mathrm{NaH}_{2} \mathrm{PO}_{4} / \mathrm{K}_{2} \mathrm{HPO}_{4}\right) \mathrm{pH} 6 \cdot 5$. The trace salts mixture is described in Table $\mathrm{I}$. Solutions of L-glutamate, L-glutamine, L-tryptophan, streptomycin sulphate and Tween 80 were sterilized by filtration and added to the other components after they had been sterilized in an autoclave at $121{ }^{\circ} \mathrm{C}$ for $20 \mathrm{~min}$.

\begin{tabular}{|c|c|c|c|}
\hline Amino acids & $\begin{array}{c}\text { Concn } \\
{\left[\mathrm{mg}(\mathrm{I} 00 \mathrm{ml})^{-1}\right]}\end{array}$ & Other components & $\begin{array}{c}\text { Concn } \\
{\left[\mu \mathrm{g}(\mathrm{roO} \mathrm{ml})^{-1}\right]}\end{array}$ \\
\hline L-Alanine & 30 & D-Biotin & 25 \\
\hline L-Arginine. $\mathrm{HCl}$ & 30 & Flavin mononucleotide & 25 \\
\hline L-Aspartic acid & 35 & Folic acid & 125 \\
\hline L-Asparagine & 35 & DL- $\alpha$-Lipoic acid & 50 \\
\hline L-Cysteine & 25 & Riboflavin & 25 \\
\hline L-Glutamic acid & 60 & Thiamin. $\mathrm{HCl}$ & 50 \\
\hline L-Glutamine & 60 & & \\
\hline Glycine & 20 & & {$\left[\mathrm{mg}(\mathrm{I} 00 \mathrm{ml})^{-1}\right]$} \\
\hline $\mathrm{L}$-Histidine. $\mathrm{HCl}$ & 20 & Soluble starch & 1500 \\
\hline L-Isoleucine & 40 & Streptomycin sulphate & 25 \\
\hline L-Leucine & 70 & & \\
\hline L-Lysine. $\mathrm{HCl}$ & 80 & & {$\left[\mathrm{ml}(\mathrm{I} O 0 \mathrm{ml})^{-1}\right]$} \\
\hline L-Methionine & 25 & Tween $80(5 \%, v / v)$ & 0.3 \\
\hline L-Phenylalanine & 40 & $\mathrm{MnCl}_{2} \cdot 4 \mathrm{H}_{2} \mathrm{O}\left(0.2 \mathrm{~g} \mathrm{l}^{-1}\right)$ & 0.5 \\
\hline L-Proline & 20 & $\mathrm{MgSO}_{4} \cdot 7 \mathrm{H}_{2} \mathrm{O}\left(10 \mathrm{~g} \mathrm{l}^{-1}\right)$ & 0.5 \\
\hline L-Serine & 30 & Trace salts & $0 \cdot \mathrm{I}$ \\
\hline L-Threonine & 30 & & \\
\hline L-Tryptophan & 50 & & \\
\hline L-Tyrosine & 15 & & \\
\hline L-Valine & 50 & & \\
\hline
\end{tabular}

D-biotin, 0.5 ; folic acid, 2.5 ; DL- $\alpha$-lipoic acid, $\mathrm{I} \cdot 0$; pyridoxal. $\mathrm{HCl}, \mathrm{I} \cdot 0$; and pyridoxamine. $\mathrm{HCl}, \mathrm{I} \cdot 0$; dissolved in $100 \mathrm{~mm}$-phosphate buffer $\left(\mathrm{NaH}_{2} \mathrm{PO}_{4} / \mathrm{K}_{2} \mathrm{HPO}_{4}\right) \mathrm{pH} 6 \cdot 5$. The mixture was diluted to half strength when used in growth media.

Assay for nicotinate. Nicotinate was assayed using Lactobacillus arabinosus $17 / 5$ and Niacin Assay Medium (Oxoid) according to the manufacturer's instructions except that all the volumes were halved. 


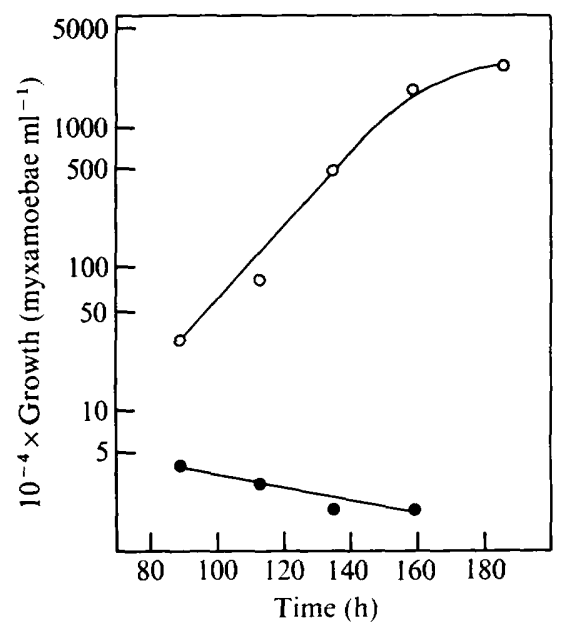

Fig. I. Requirement for flavin for growth of $D$. discoideum. $O$, Growth in TEV medium plus pantothenate, nicotinate, pyridoxal and pyridoxamine (all at $0.5 \mu \mathrm{g} \mathrm{ml}^{-1}$ ); 0 , growth in the same medium but lacking riboflavin and flavin mononucleotide.

Chemicals. Tween 80, DNA, RNA, streptomycin sulphate and all vitamins, amino acids and nucleosides were purchased from Sigma. Tryptone (a tryptic digest of casein) was from Oxoid, the vitamins being removed by treatment with charcoal as described by Roberts \& Snell (I944) except that $\mathrm{HCl}$ was used instead of acetic acid to acidify the Tryptone solution. All other chemicals, including soluble starch, were of the highest purity available from BDH or Fisons Scientific Apparatus.

RESULTS

\section{Identification of vitamin requirements}

Myxamoebae were adapted to growth in medium containing predetermined vitamin concentrations by a stepwise process of replacing the complex components of the HL5 medium plus soluble starch with simpler components. At each stage, populations of myxamoebae with mean doubling times of 8 to $\mathrm{I} 2 \mathrm{~h}$ were selected for growth in the modified media.

First, the yeast extract in the HL5 medium was replaced by the vitamin mixture (see Methods), DNA $\left(250 \mu \mathrm{g} \mathrm{ml}^{-1}\right), \operatorname{RNA}\left(750 \mu \mathrm{g} \mathrm{ml}^{-1}\right), \mathrm{MgSO}_{4} \cdot 7 \mathrm{H}_{2} \mathrm{O}\left(50 \mu \mathrm{g} \mathrm{m}^{-1}\right)$ and $\mathrm{MnSO}_{4}$. ${ }_{4} \mathrm{H}_{2} \mathrm{O}\left(0.5 \mu \mathrm{g} \mathrm{ml}^{-1}\right)$. Growth was initially poor but improved on subculturing to resemble that in $\mathrm{HL}_{5}$ medium plus soluble starch. Bacteriological peptone was then replaced with Tryptone (20 $\mathrm{m} \mathrm{m} \mathrm{ml}^{-1}$ ) and the DNA and RNA with nucleosides (deoxyadenosine, deoxyguanosine, deoxycytidine and thymidine, $14 \mu \mathrm{g} \mathrm{ml}^{-1}$ final concentration; adenosine, guanosine, cytidine and uridine, $43 \mu \mathrm{g} \mathrm{m}^{-1}$ final concentration). Again, growth was poor at first but improved after two subcultures. Later it was found that there was no requirement for the nucleosides although there was a lag period of about a week before the myxamoebae started to grow when the nucleosides were first omitted from the medium.

Tryptone, treated with charcoal to ensure that it was free of vitamins (Roberts \& Snell, 1944), was then used in the medium. L-Phenylalanine and L-tryptophan (both at $0.5 \mathrm{mg}$ $\mathrm{ml}^{-1}$ ), and a mixture of inorganic salts (described in Table $\mathrm{I}$ ) had to be added to the medium for it to support growth of myxamoebae. L-Tyrosine $\left(0.2 \mathrm{mg} \mathrm{ml}^{-1}\right)$ was also included since it stimulated growth.

Finally, each vitamin was omitted in turn from the medium. Growth was slower and the 
Table 3. Growth of myxamoebae in AV medium deficient in essential vitamins

Myxamoebae were grown to a density of $5 \times 10^{6}$ myxamoebae $\mathrm{ml}^{-1}$ in AV medium. After washing with sterile $50 \mathrm{~mm}$-phosphate buffer $\left(\mathrm{NaH}_{2} \mathrm{PO}_{4} / \mathrm{K}_{2} \mathrm{HPO}_{4}\right)$ pH 6.5, they were used to inoculate cultures in AV medium deficient in essential vitamins at initial densities of $2 \times 10^{4}$ myxamoebae $\mathrm{ml}^{-1}$.

$\begin{array}{lc}\text { Vitamin omitted from AV medium } & \begin{array}{c}\text { Final growth yield } \\ \text { (myxamoebae } \mathrm{ml}^{-1} \text { ) }\end{array} \\ \text { None } & 7.4 \times 10^{6} \\ \text { Biotin } & 3.7 \times 10^{6} \\ \text { Flavin mononucleotide+riboflavin } & \text { No growth detected } \\ \text { Folate } & \text { No growth detected } \\ \text { Lipoate } & 1 \cdot 5 \times 10^{6} \\ \text { Thiamin } & 3.0 \times 10^{5}\end{array}$

growth yield was reduced when folate, lipoate, thiamin or biotin was omitted, confirming previous findings based on studies of myxamoebal growth with vitamin-depleted auxotrophs of Escherichia coli (Watts \& Guest, 1975). In addition, a requirement for flavin, that could be satisfied by either riboflavin or flavin mononucleotide, was found (Fig. I).

There was no detectable requirement for nicotinate, pantothenate or vitamin B6 and myxamoebae have been grown for many generations in TEV medium (Table 1 ) to which none of these three vitamins had been added. It was possible that the Tryptone was still contaminated with sufficient of the three vitamins to support growth of the myxamoebae, but assays of the TEV medium showed that it was essentially free of nicotinate (less than $0.005 \mu \mathrm{g} \mathrm{ml}^{-1}$ ). It was also possible to replace the Tryptone with a mixture of pure amino acids and to grow myxamoebae in a defined (AV) medium (see below). There was no requirement for pantothenate, nicotinate or vitamin B6 for growth in this medium and it may be concluded that the three vitamins are not essential for growth of $D$. discoideum. The growth rate and final growth yield were reduced when the three vitamins were added to AV medium and they may be inhibitory to growth in this defined medium.

Omission of biotin, flavin mononucleotide plus riboflavin, folate, lipoate or thiamin from the AV medium led to reductions in the final growth yields (Table 3) and confirmed that these vitamins were essential for myxamoebal growth.

\section{Growth of myxamoebae in TEV medium}

Myxamoebae that had been maintained in HL5 medium grew extremely slowly on transfer to TEV medium whereas adapted myxamoebae grew with a mean doubling time of about $12 \mathrm{~h}$ to a final density of $2 \times 10^{7}$ to $3 \times 10^{7}$ myxamoebae $\mathrm{ml}^{-1}$. They also grew in the medium containing glucose $(86 \mathrm{~mm})$ instead of soluble starch. Myxamoebae grown in TEV medium would, after further growth with Aerobacter aerogenes on SM plates (Sussman, 1966), aggregate and develop into fruiting bodies that were much smaller than those formed in similar conditions by myxamoebae of the Ax-2 strain that had not been adapted to growth in TEV medium. Spores from such fruiting bodies germinated in the TEV medium giving viable myxamoebae and it would seem that the ability to grow in TEV medium is a stable character of the adapted myxamoebae. Myxamoebae also aggregated and formed fruiting bodies on Millipore filters (Sussman, I966) after growth in TEV medium.

When growth reached the stationary phase in all the media containing Tryptone, the myxamoebae secreted a soluble, brown pigment. 


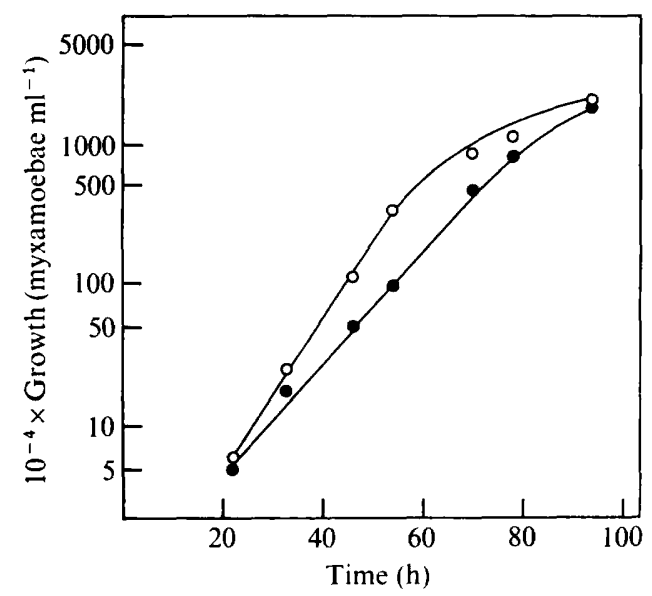

Fig. 2

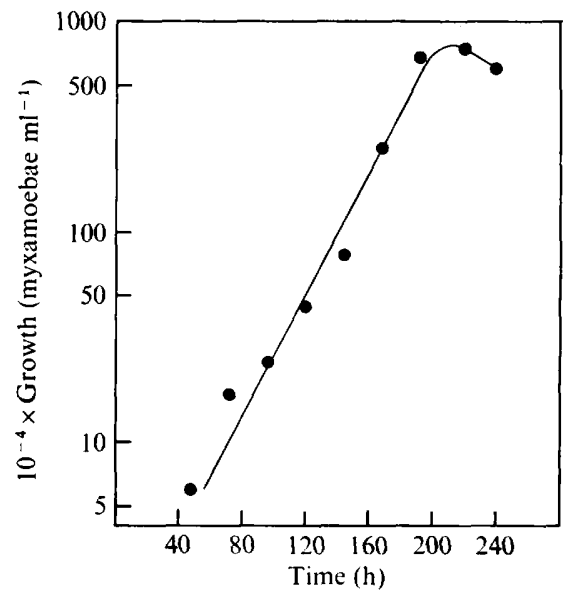

Fig. 3

Fig. 2. Effect of Tween 80 on growth of $D$. discoideum. $O$, Growth in HL5 medium containing soluble starch (15 mg ml-1) and Tween $80(0.015 \%)$; growth in HL5 medium containing soluble starch ( $15 \mathrm{mg} \mathrm{ml}^{-1}$ ).

Fig. 3. Growth of D. discoideum in AV medium.

\section{Growth of myxamoebae in HL5 medium containing soluble starch and Tween 80}

The mean doubling time for growth of myxamoebae of strain Ax-2 in HL5 medium containing soluble starch was about $8 \mathrm{~h}$ but decreased to 5 to $6 \mathrm{~h}$ if the detergent Tween 80 $(0.015 \%, v / v)$ was added at the same time as the medium was inoculated with myxamoebae (Fig. 2). Tween 80 is usually added to microbial growth media as a source of oleate but it seems that it stimulated myxamoebal growth because it caused starch precipitation and not because it was a nutrient. Thus, growth was similarly stimulated in the absence of Tween 80 by adding potato starch which precipitated spontaneously in the HL5 medium. Furthermore, Tween 80 did not stimulate growth in HL5 medium containing $86 \mathrm{~mm}$-glucose where no precipitate was formed. This proved important in developing a defined medium to support growth of myxamoebae.

\section{Growth of myxamoebae in defined medium}

Myxamoebae adapted to growth in TEV medium would not grow in a similar medium where the Tryptone was replaced by a mixture of L-amino acids at the concentrations given in Table 2. (These amino acid concentrations were approximately in the same proportions as in Tryptone.) However, the myxamoebae grew when Tryptone (I0 $\mathrm{mg} \mathrm{ml}^{-1}$ ) was also included in the medium. It was possible to maintain growth with gradually decreasing concentrations of Tryptone though the mean doubling time increased to $24 \mathrm{~h}$ and, when the initial Tryptone concentration in the medium was below $200 \mu \mathrm{g} \mathrm{ml}^{-1}$, the growth yield decreased to below $10^{7}$ myxamoebae $\mathrm{ml}^{-1}$. There was still no growth in the absence of Tryptone and it seemed that either the Tryptone contained an unidentified micro-nutrient or it was inducing growth by stimulating the myxamoebae to utilize the amino acids and vitamins in the growth medium. If the latter explanation were correct, it seemed probable that the same effect would be obtained by addition of Tween 80 to the medium in place of the Tryptone since the starch precipitate then formed would also be expected to stimulate uptake of nutrients by the myxamoebae. At first, Tween 80 (0.015\%) was added in the presence of Tryptone $\left(200 \mu \mathrm{g} \mathrm{ml}^{-1}\right)$, but, when the Tryptone was omitted, myxamoebal growth con- 
tinued. Myxamoebae were then grown for many generations in the absence of Tryptone but growth was slow in this defined (AV) medium (Table 2), the mean doubling time being 20 to $24 \mathrm{~h}$ (Fig. 3). There was no growth if Tween 80 was omitted from the medium. Myxamoebae maintained in TEV medium did not grow on direct transfer to AV medium.

Myxamoebae grew in HL5 medium containing starch or in the TEV medium to a final density of $2 \times 10^{7}$ to $3 \times 10^{7}$ myxamoebae $\mathrm{ml}^{-1}$ but the final growth yield was lower in the AV medium where it was $7 \times 10^{6}$ to $9 \times 10^{6}$ myxamoebae $\mathrm{ml}^{-1}$. It seems that depletion of the starch precipitate may have been limiting growth rather than depletion of an amino acid or vitamin. Analyses of the amino acid concentrations in the AV medium, before and after growth of myxamoebae, showed that no amino acid was significantly depleted during myxamoebal growth and the vitamins present in the defined medium were at concentrations that allowed growth to $2 \times 10^{7}$ to $3 \times 10^{7}$ myxamoebae $\mathrm{ml}^{-1}$ in TEV medium. It was not possible to increase the growth yield by raising the concentration of Tween 80 in the defined medium to increase starch precipitation, presumably because the Tween 80 was toxic at such concentrations.

After growth on plates of SM medium in dual culture with Aerobacter aerogenes (Sussman, I966), myxamoebae of the strain adapted to growth in the AV medium would not aggregate. This difficulty was previously encountered when myxamoebae were first adapted to axenic growth in HL5 medium during isolation of the Ax-2 strain (Watts \& Ashworth, 1970) and presumably it can again be overcome.

\section{DISCUSSION}

It has been shown that myxamoebae of Dictyostelium discoideum grow in a defined medium containing L-amino acids, B vitamins, starch, inorganic salts and the detergent Tween 80 . Since it is probable that the Tween 80 is used only to cause starch precipitation, rather than as an essential nutrient, the nutritional requirements for growth of the myxamoebae are not unusual. The unique feature of myxamoebal growth in the defined medium is its complete dependence on the presence of a precipitate of starch. In the absence of the precipitate, the myxamoebae not only fail to grow but soon diminish in size and die. Starch particles also stimulate growth in the semi-defined HL5 medium and this is similar to the effect of precipitates, formed from inorganic salts, on the growth of Tetrahymena pyriformis and Acanthamoeba in semi-defined media where precipitates seem to induce phagocytosis and so stimulate uptake of nutrients (Rasmussen \& Kludt, 1970; Holst-Sørensen \& Rasmussen, I97I).

Although the defined medium contains only those vitamins essential to myxamoebal growth (biotin, folate, lipoate, riboflavin plus flavin mononucleotide, and thiamin), it does contain all of the $20 \mathrm{~L}$-amino acids commonly found in proteins. However, it should now be possible to identify the essential amino acids so that myxamoebae can be grown in a minimal defined medium.

Selection of auxotrophic mutants of $D$. discoideum would be helpful in genetic studies of slime mould development. Such studies have previously been hampered by the lack of a defined medium in which to select mutants and by the difficulties in growing myxamoebae axenically on agar plates (Watts \& Ashworth, I970). Now that a defined medium supporting growth of the myxamoebae is available, it should be worthwhile investigating means of overcoming the latter problem.

I thank Miss Katrina Szablij for skilled technical assistance and Mrs Linda Gibb for the amino acid analyses. I am grateful for the help received from Dr J. R. Guest and Dr W. Ferdinand. 


\section{REFERENCES}

Holst-Sørensen, H. \& Rasmussen, L. (197I). Growth promoting effects of particulate material in cultures of Acanthamoeba. Comptes rendus des travaux du Laboratoire Carlsberg 38, 163-170.

Rasmussen, L. \& KLUdT, T. R. (1970). Particulate material as a prerequisite for rapid cell multiplication in Tetrahymena cultures. Experimental Cell Research 59, 457-463.

Roberts, E. C. \& SNELl, E. E. (1944). An improved medium for microbiological assays with Lactobacillus casei. Journal of Biological Chemistry 163, 499-509.

Sussman, M. (1966). Biochemical and genetic methods in the study of cellular slime mold development. In Methods in Cell Physiology, vol. 2, pp. 397-410. Edited by D. M. Prescott. New York and London: Academic Press.

Watts, D. J. \& Ashworth, J. M. (1970). Growth of myxamoebae of the cellular slime mould Dictyostelium discoideum in axenic culture. Biochemical Journal 119, $171-174$.

WATTS, D. J. \& GUEST, J. R. (I 975). Studies on the vitamin nutrition of the cellular slime mould Dictyostelium discoideum. Journal of General Microbiology 86, 333-342. 